\title{
Mathematical modelingof heat and mass transfer processes in the adsorbers of the air purification system
}

\author{
E.I. Starovoitov ${ }^{1}$, A.Y. Ershova ${ }^{2}$, Elena L. Kuznetsova ${ }^{3}$ \\ ${ }^{1}$ Department of Building Mechanics Belarusian State University of Transport 246653, 34 Kirov Str., Gomel, \\ Republic of Belarus \\ ${ }^{2,3}$ Moscow Aviation Institute (National Research University), Volokolamskoeshosse, 4, 125993, Moscow, Russia \\ ${ }^{2}$ vida_ku@mail.ru
}

Article History: Received: 11 January 2021: Accepted: 27 February 2021; Published online: 5 April 2021 Abstract:The present work is devoted to the study of the processes of heat and mass transfer in the adsorbers of the preliminary drying unit of the atmosphere purification system. A mathematical model has been developed that adequately reflects the physical processes at all stages of the adsorption cycle.Algorithms for solving problems and programs for calculating heat and mass transfer processes in an adsorption regenerated installation are obtained, results of parametric calculations of heat and mass transfer processes at each stage of the adsorption cycle and for the entire cycle as a whole are obtained.

Keywords:air purification, adsorption, heat and mass transfer, mathematical model

\section{Introduction}

In atmospheric purification systems, carbon dioxide is removed from the air by using the adsorption phenomenon. As a physical phenomenon, adsorption is widely used for directed formation of layers of various substances on a substrate surface [1-14]. A lot of coatings with modified properties can be attributed to the polymers, nanomaterials etc. [15-25]. Before the air is cleaned from carbon dioxide, it is dried in a preliminary drying unit also by passing through an adsorbent bed. The pre-drying unit consists of two alternately operating adsorbers covered with a granular absorber - silica gel. One of the adsorbers works to dry the air, and the second is regenerated at this time. The duration of each half-cycle is usually 1 hour, and it is determined by the appearance behind the adsorbent layer of the concentration of water vapor in the air at a level of $-20 \mathrm{C}$ according to the dew point temperature. Providing such a degree of air drying requires constant energy consumption (up to $240 \mathrm{~W}$ ), which is used to heat the air to regenerate the adsorbent.

The solution of the set tasks requires a large amount of theoretical and experimental work. Due to the large number of parameters that determine the efficiency of the drying process, a complete analysis of the cycle is largely determined by the presence and implementation of reliable mathematical models and calculation algorithms in engineering practice [26-32]. On their basis, it is possible both to take into account the peculiarities of the flow of heat and mass transfer processes at each step of the cycle, and their interaction during the transition from the previous step to the next.

\section{Systems of equations simulating the adsorption process}

In accordance with the description of the physical processes of adsorption, it is necessary to write a system of equations describing the dynamics of sorption in the layer of the studied system [33-38]. Experimental studies have shown that the processes occurring in the sorbent layer are nonstationary and one-dimensional (we neglect the change in parameters along the layer height). In the general case, when the gas mixture is passed through the adsorption layer, the sought functions $\rho_{i}(x, t), a_{i}(x, t)$ and $T(x, t)$ must satisfy the system of equations describing the balance of matter and energy in the layer, and also reflecting the kinetics and statics of adsorption.

The first equation reflecting the balance of matter in the layer can be written in the following form:

$$
\begin{aligned}
& -\frac{\partial\left(U \rho_{i}\right)}{\partial x}+\frac{\partial}{\partial x} D_{i}\left(T, \rho_{i}\right) \frac{\partial \rho_{i}}{\partial x}=\frac{\partial a_{i}}{\partial t}+\varepsilon \frac{\partial \rho_{i}}{\partial t} \\
& i=1 \div(N-1)
\end{aligned}
$$

where $\quad N$ - number of gas mixture components. The first term expresses the transfer of matter due to the presence of flow velocity, the second longitudinal diffusion. The right side conveys the increase in concentration and the increase in the value of the sorbed substance, $\rho$ and $a$ here the average values of concentration and sorption, calculated per unit volume in a given place of the layer; $D$ - is the diffusion 
coefficient; $\varepsilon$ - the porosity of the substance. The concentration and sorption values are averaged along the plane perpendicular to the $x$ axis, since we assumed that $\rho$ depends only on $x$. In this case, the values $U, D_{i}$ n Eq. (1) are considered effective, not true, i.e. averaged over the length of the average distance between the granules. The convective transfer rate $U$, determined from the condition

$$
U \sum_{i=1}^{N} \rho_{i}=\sum_{i=1}^{N} \rho_{i} U_{i}
$$

Density of the diffusion flux of the $i$-th component $-D_{i}\left(T, \rho_{i}\right) \frac{\partial \rho_{i}}{\partial x}=j_{i}$ defined as $j_{i}=\rho_{i} U_{i}-\rho U$

The continuity equation as a whole is obtained by summing equations (1) over $i$.

$$
\varepsilon \frac{\partial \rho}{\partial t}+\frac{\partial(U \rho)}{\partial x}=-\sum_{j=1}^{N} \frac{\partial a_{j}}{\partial t}
$$

Instead of equation (2), the continuity equation for the $i$-th component can be used. Equation (2) corresponds to the law of conservation of matter and is not associated with any special hypotheses.

The equation reflecting the kinetics of the process is written in the following form:

$$
\frac{\partial a_{i}}{\partial t}=\beta_{i}\left(a_{i}^{*}-a_{i}\right) i=1 \div(N-1) \text {, }
$$

The following equation is the energy equation for the charge and filter gas, which can be written in the following form:

$$
\frac{\partial}{\partial t}\left(\left[\rho_{s} C_{s}+\sum_{i=1}^{N} a_{i} C_{i}\right] T\right)+\frac{\partial\left(\rho U C_{p} T\right)}{\partial x}=\frac{\partial}{\partial x} \lambda_{s} \frac{\partial T}{\partial x}-\sum_{i=1}^{N} \Delta H_{i} \frac{\partial a_{i}}{\partial t}
$$

where $\rho_{s}$ - bulk density of dry charge; $C_{s}$ - specific heat of dry charge; $C_{i}$ - specific heat $i$-th component in the liquid phase; $C_{p}$ - specific heat of gas at constant pressure; $\lambda_{s}$ - heat conductivity coefficient of the charge; $\Delta H_{i}$ - specific enthalpy of condensation of the $i$-th component.

The change in the internal energy per unit volume is determined by convective heat transfer and thermal conductivity, as well as the release or absorption of heat in the layer during sorption or desorption, is described by the term in the equation (4):

$$
-\sum_{i=1}^{N} \Delta H_{i} \frac{\partial a_{i}}{\partial t} \text {. }
$$

To close the system of equations, it must be supplemented with equations for $a_{i}^{*}$, i.e. the previously considered sorption isotherms, as well as the equation of state:

$$
\begin{aligned}
& a_{i}^{*}=\varphi\left(T, \rho_{i}\right) \quad i=1 \div(N-1), \\
& p=\rho R T .
\end{aligned}
$$

The specific form of the function in the case of absorption of water vapor is determined from the experiment.

Thus, the following system of equations is obtained:

$$
\begin{aligned}
& -\frac{\partial\left(U \rho_{i}\right)}{\partial x}+\frac{\partial}{\partial x} D_{i}\left(T, \rho_{i}\right) \frac{\partial \rho_{i}}{\partial x}=\frac{\partial a_{i}}{\partial t}+\varepsilon \frac{\partial \rho_{i}}{\partial t} \\
& \varepsilon \frac{\partial \rho}{\partial t}+\frac{\partial(U \rho)}{\partial x}=-\sum_{i=1}^{N} \frac{\partial a_{i}}{\partial t} \\
& \frac{\partial}{\partial t}\left(\left[\rho_{s} C_{s}+\sum_{i=1}^{N} a_{i} C_{i}\right] T\right)+\frac{\partial\left(\rho U C_{p} T\right)}{\partial x}=\frac{\partial}{\partial x} \lambda_{s} \frac{\partial T}{\partial x}-\sum_{i=1}^{N} \Delta H_{i} \frac{\partial a_{i}}{\partial t} \\
& \frac{\partial a_{i}}{\partial t}=\beta_{i}\left(a_{i}^{*}-a_{i}\right) \quad i=1 \div(N-1) \\
& a^{*}=\varphi\left(T, \rho_{i}\right) \quad i=1 \div(N-1) \\
& p=\rho R T
\end{aligned}
$$

Unknown quantities of the system of equations: 


$$
\begin{aligned}
& \rho_{i}(i=1 \div(N-1)) ; T \\
& a_{i}(i=1 \div(N-1)) ; \rho \\
& a_{i}^{*}(i=1 \div(N-1)) ; U \text {. Number of unknowns }-3 N .
\end{aligned}
$$

Number of equations:

$$
\text { (3.1) - }(N-1) ; \quad(3.2)-1 ; \quad \text { (3.3) - 1; (3.4) - (N-1); (3.5) - (N-1); (3.6) - } 1 .
$$

In total, the number of equations is $3 N$. The system is closed.

This system of differential equations must also be supplemented with initial and boundary conditions. The initial conditions specify the distributions of the functions $\rho$, $a$ and $T$ along the sorbent layer at the initial moment of time. The boundary conditions determine the required functions on the boundaries of the system.

\section{Determination of essential physical factors and boundary conditions}

Determination of essential physical factors for the equation of continuity of the i-th component. Let us compare the rates of diffusion and convection processes in the layer. Estimation of the characteristic times of diffusion and convection:

$$
\tau_{\text {кон. }} \sim \frac{l}{U} \quad l \text {-sorbent layer thickness. }
$$

$\tau_{\text {кон }}$ - the time during which the concentration front shifts by the layer length as a result of convective transfer. For diffusion, the characteristic time will be:

$$
\tau_{\partial u \phi .} \sim \frac{l}{U_{\partial u \phi .}} .
$$

$U_{\partial u \phi .}-$ characteristic diffusion rate, defined as:

$$
U_{\partial u \phi .}=U_{i}-U \sim\left|\frac{j_{i}}{\rho_{i}}\right| \text {; }
$$

$\rho_{i}$ - layer-average density of the $i$-th component $\left|j_{i}\right| \approx D_{i} \frac{\Delta \rho_{i}}{l} ; \Delta \rho_{i}$ - difference in concentration at the inlet and outlet from the layer; ${ }_{i}$ - layer average longitudinal diffusion coefficient. Thus $\tau_{\text {диф. }} \sim \frac{l}{\left|\frac{j}{\rho_{i}}\right|}=\frac{l^{2}}{D \frac{\Delta \rho_{i}}{\rho_{i}}}$,

Provided that

$$
D_{i} \frac{\Delta \rho_{i}}{\rho_{i}}<<l U
$$

it turns out that $\tau_{\text {кон. }} / \tau_{\text {диф. }}<<1$, i.e. at low gradients of component densities and high average (convection) velocities, the convection process will be decisive.

Using the values of the parameters of the atmosphere regeneration plant on board the orbital station, the following numerical estimates are carried out. Total air consumption at the sorption stage is approximately 25 $\mathrm{m}^{3} / \mathrm{h}$, cross-sectional area of the bed $F=0,06158 \mathrm{~m}^{2}, l=0,1 \mathrm{~m}$, diffusion coefficient of water vapor in air (at atmospheric pressure and temperature $\left.20^{\circ} \mathrm{C}\right) 2 \cdot 10^{-5} \mathrm{~m}^{2} / \mathrm{c}$. Then the characteristic times are: $\tau_{\text {кон. }} \approx 0,9 \mathrm{c}$, $\tau_{\partial и ф . ~} \sim 500 c$. Thus, diffusion occurs three orders of magnitude slower than convection. Consequently, diffusion can be disregarded in the process of mass transfer and in equations (1) the term responsible for the diffusion flux can be discarded.

Other simpler equations are obtained: $\varepsilon \frac{\partial \rho_{i}}{\partial t}+\frac{\partial\left(U \rho_{i}\right)}{\partial x}=-\frac{\partial a_{i}}{\partial t}$.

2) A similar estimate is carried out for the energy conservation equation. 
Members are compared $\frac{\partial\left(\rho U C_{p} T\right)}{\partial x}$ and $\frac{\partial}{\partial x} \lambda_{s} \frac{\partial T}{\partial x}$. The characteristic time of convective energy transfer, as well as for mass transfer, is $l / U=0,9 c$. The characteristic time of thermal conductivity will be $\tau_{\text {T.П. }} \sim \frac{l}{U_{\text {T.П. }}}$; где $U_{\text {T.П. }} \sim\left|\frac{S}{\left.\mid \rho_{s} C_{s}+\sum a_{i} C_{i}\right]}\right||S| \sim \lambda_{s} \frac{\Delta T}{l}$, where $S$ - energy flux density.

We denote $g=\rho_{s} C_{s}+\sum_{i}^{N} a_{i} C_{i}-$ total heat capacity per unit volume of a layer. Then $U_{\text {T.П. }} \sim\left|\frac{S}{g T}\right| \sim \lambda_{s} \frac{\Delta T}{l} \cdot \frac{1}{g T} \sim \frac{\lambda_{s}}{\lg }$. After substitution of the corresponding values $\rho_{s}=889 \mathrm{~kg} / \mathrm{m}^{3}$; $C_{s}=840 \mathrm{~J} / \mathrm{kg} \cdot \mathrm{K}$. The specific heat of absorbed moisture can be neglected $a_{\mathrm{H}_{2} \mathrm{O}} C_{\mathrm{H}_{2} \mathrm{O}}\left\langle\left\langle\rho_{s} C_{s}\right.\right.$ at $a_{\mathrm{H}_{2} \mathrm{O}} \sim 5$ $\left.\mathrm{kg} / \mathrm{m}^{3} ; C_{\mathrm{H}_{2} \mathrm{O}}=4200 \mathrm{~J} / \mathrm{kg} \cdot \mathrm{K} ; C_{s} \rho_{s} \sim 6 \cdot 10^{5} \mathrm{~J} / \mathrm{m}^{3} \cdot \mathrm{K} ; a_{\mathrm{H}_{2} \mathrm{O}} C_{\mathrm{H}_{2} \mathrm{O}} \sim 2 \cdot 10^{4} \mathrm{~J} / \mathrm{m}^{3} \cdot \mathrm{K}\right)$ we get $\tau_{T . \Pi .} \sim 6 \cdot 10^{4} \mathrm{c}$. Thus, the transfer of heat within the layer by means of thermal conduction occurs 5 orders of magnitude slower than with convective heat transfer. Therefore, the thermal conductivity in the energy equation can be neglected.

After discarding the terms describing insignificant physical factors, we finally obtain the system of equations.

$$
\begin{aligned}
& \varepsilon \frac{\partial \rho_{i}}{\partial t}+\frac{\partial\left(U \rho_{i}\right)}{\partial x}=-\frac{\partial a_{i}}{\partial t} \\
& \varepsilon \frac{\partial \rho}{\partial t}+\frac{\partial(U \rho)}{\partial x}=-\sum_{j=1}^{N} \frac{\partial a_{j}}{\partial t} \\
& \frac{\partial}{\partial t}\left(\left[\rho_{s} C_{s}+\sum_{i=1}^{N} a_{i} C_{i}\right] T\right)+\frac{\partial\left(\rho U C_{p} T\right)}{\partial x}=-\sum_{i=1}^{N} \Delta H_{i} \frac{\partial a_{i}}{\partial t} \\
& p=\rho R T \\
& \frac{\partial a_{i}}{\partial t}=\beta_{i}\left(a_{i}^{*}-a_{i}\right) \\
& a_{i}^{*}=\varphi\left(T, \rho_{i}\right)
\end{aligned}
$$

Let us write out the boundary conditions:

1) The continuity equations for the $i$-th component and the energy conservation equation before neglecting insignificant physical factors were equations of the second order, after dropping the terms describing diffusion and thermal conductivity, they became equations of the first order. The original equations (1), (2) are parabolic equations, which requires the setting of boundary conditions on both boundaries (at the input and output). Equations (8) and (10) of the 1st order, for which the boundary conditions are specified only on one boundary the upper in the stream.

2) Boundary and initial conditions.

Border conditions.

$$
\begin{aligned}
& \text { When } x=x_{1} \quad \rho_{i}\left(x_{1} ; t\right)=\rho_{i}^{(1)}(t) \quad \forall i=1 \div(N-1) \\
& T\left(x_{1} ; t\right)=T_{1}(t) \\
& U\left(x_{1} ; t\right)=\frac{G}{F}
\end{aligned}
$$

Initial conditions:

$$
\begin{aligned}
& \text { When } t=0 \quad \rho_{i}(x, 0)=\rho_{i}^{(0)}(x) \\
& a_{i}(x, 0)=a_{i}^{(0)}(x) \\
& T(x, 0)=T^{(0)}(x)
\end{aligned}
$$


The equations obtained make it possible to simulate adsorption processes and carry out numerical experiments.

\section{Conclusions}

Onthebasisof the obtained expressions, it is possible both to take into account the peculiarities of the flow of heat and mass transfer processes at each of the steps of the adsorption-desorption cycle, and their interaction during the transition from the previous step to the next. Numerical experiments on predicting the behavior of an adsorption system with different organization of cycle steps make it possible not only to reasonably determine the technological parameters of the process, but in many cases also to reduce the amount of experimental research.

\section{Acknowledgement}

This work was carried out with the financial support of RFBR, project No. 20-08-00707.

\section{References}

1. Bulychev, N.A., Rabinskiy, L.N. Ceramic nanostructures obtained by acoustoplasma technique//Nanoscience and Technology: An International Journal, 2019, 10(3), p. 279-286.

2. Bulychev, N.A., Rabinskiy, L.N., Tushavina, O.V. Effect of intense mechanical vibration of ultrasonic frequency on thermal unstable low-temperature plasma// Nanoscience and Technology: An International Journal, 2020, 11(1), p. 15-21.

3. Rabinskiy, L.N., Sitnikov, S.A. Development of technologies for obtaining composite material based on silicone binder for its further use in space electric rocket engines// Periodico Tche Quimica, 2018, 15(Special Issue 1), p. 390-395.

4. N.A. Bulychev, M.A. Kazaryan. Optical Properties of Zinc Oxide Nanoparticles Synthesized in Plasma Discharge in Liquid under Ultrasonic Cavitation, Proceedings of SPIE, 2019, Vol. 11322, article number 1132219.

5. N.A. Bulychev, A.V. Ivanov. Effect of vibration on structure and properties of polymeric membranes, International Journal of Nanotechnology, 2019, Vol. 16, Nos. 6/7/8/9/10, pp. $334-343$.

6. N.A. Bulychev, A.V. Ivanov. Nanostructure of Organic-Inorganic Composite Materials Based on Polymer Hydrogels, International Journal of Nanotechnology, 2019, Vol. 16, Nos. 6/7/8/9/10, pp. 344 355.

7. N.A. Bulychev, A.V. Ivanov. Study of Nanostructure of Polymer Adsorption Layers on the Particles Surface of Titanium Dioxide, International Journal of Nanotechnology, 2019, Vol. 16, Nos. 6/7/8/9/10, pp. $356-365$.

8. O.A. Butusova. Surface Modification of Titanium Dioxide Microparticles Under Ultrasonic Treatment, International Journal of Pharmaceutical Research, 2020, Vol. 12, I. 4, pp. 2292-2296.

9. O.A. Butusova. Stabilization of Carbon Microparticles by High-Molecular Surfactants, International Journal of Pharmaceutical Research, 2020, Vol. 12, Supplementary Issue 2, pp. 1147-1151.

10. O.A. Butusova. Vinyl Ether Copolymers as Stabilizers of Carbon Black Suspensions, International Journal of Pharmaceutical Research, 2020, Vol. 12, Supplementary Issue 2, pp. 1152-1155.

11. Yu.V. Ioni. Synthesis of Metal Oxide Nanoparticles and Formation of Nanostructured Layers on Surfaces under Ultrasonic Vibrations, International Journal of Pharmaceutical Research, 2020, Vol. 12, Issue 4, pp. 3432-3435.

12. O.A. Butusova. Adsorption Behaviour of Ethylhydroxyethyl Cellulose on the Surface of Microparticles of Titanium and Ferrous Oxides, International Journal of Pharmaceutical Research, 2020, Vol. 12, Supplementary Issue 2, pp. 1156-1159.

13. M.O. Kaptakov. Effect of Ultrasonic Treatment on Stability of TiO2 Aqueous Dispersions in Presence of Water-Soluble Polymers, International Journal of Pharmaceutical Research, 2020, Vol. 12, Supplementary Issue 2, pp. 1821-1824.

14. B.A. Garibyan. Mechanical Properties of Electroconductive Ceramics, International Journal of Pharmaceutical Research, 2020, Vol. 12, Supplementary Issue 2, pp. 1825-1828.

15. B.A. Garibyan. Enhancement of Mechanical Properties of Inorganic Glass under Ultrasonic Treatment, International Journal of Pharmaceutical Research, 2020, Vol. 12, Supplementary Issue 2, pp. 18291832. 
16. B.A. Garibyan. Modelling of Technical Parameters of Discharge Reactor for Polymer Treatment, International Journal of Pharmaceutical Research, 2020, Vol. 12, Supplementary Issue 2, pp. 18331837.

17. A.N. Tarasova. Vibration-based Method for Mechanochemical Coating Metallic Surfaces, International Journal of Pharmaceutical Research, 2020, Vol. 12, Supplementary Issue 2, pp. 1160-1168.

18. M.O. Kaptakov. Catalytic Desulfuration of Oil Products under Ultrasonic Treatment, International Journal of Pharmaceutical Research, 2020, Vol. 12, Supplementary Issue 2, pp. 1838-1843.

19. M.O. Kaptakov. Enhancement of Quality of Oil Products under Ultrasonic Treatment, International Journal of Pharmaceutical Research, 2020, Vol. 12, Supplementary Issue 2, pp. 1851-1855.

20. Yu.V. Ioni, A. Ethiraj. Study of Microparticles Surface Modification by Electrokinetic Potential Measuring, International Journal of Pharmaceutical Research, 2020, Vol. 12, Issue 4, pp. 3436-3439.

21. A.N. Tarasova. Effect of Reagent Concentrations on Equilibria in Water-Soluble Complexes, International Journal of Pharmaceutical Research, 2020, Vol. 12, Supplementary Issue 2, pp. 11691172.

22. Yu.V. Ioni. Effect of Ultrasonic Treatment on Properties of Aqueous Dispersions of Inorganic and Organic Particles in Presence of Water-Soluble Polymers, International Journal of Pharmaceutical Research, 2020, Vol. 12, Issue 4, pp. 3440-3442.

23. A.N. Tarasova. Effect of Vibration on Physical Properties of Polymeric Latexes, International Journal of Pharmaceutical Research, 2020, Vol. 12, Supplementary Issue 2, pp. 1173-1180.

24. Yu.V. Ioni, A. Ethiraj. New Tailor-Made Polymer Stabilizers for Aqueous Dispersions of Hydrophobic Carbon Nanoparticles, International Journal of Pharmaceutical Research, 2020, Vol. 12, Issue 4, pp. 3443-3446.

25. Yu.V. Ioni. Nanoparticles of noble metals on the surface of graphene flakes, Periodico Tche Quimica, 2020, Vol. 17, No. 36, pp. 1199-1211.

26. Rabinskiy, L.N., Tushavina, O.V., Formalev, V.F. Mathematical modeling of heat and mass transfer in shock layer on dimmed bodies at aerodynamic heating of aircraft// Asia Life Sciences, 2019, (2), p. 897-911.

27. Formalev, V.F., Kartashov, É.M., Kolesnik, S.A. On the Dynamics of Motion and Reflection of Temperature Solitons in Wave Heat Transfer in Limited Regions // Journal of Engineering Physics and Thermophysics, 2020, 93(1), p. 10-15.

28. Antufev, B.A., Egorova, O.V., Rabinskiy, L.N. Quasi-static stability of a ribbed shell interacting with moving load// INCAS Bulletin, 2019, 11, p. 33-39.

29. Bodryshev, V.V., Babaytsev, A.V., Rabinskiy, L.N. Investigation of processes of deformation of plastic materials with the help of digital image processing// Periodico Tche Quimica, 2019, 16(33), p. 865-876.

30. Anikin V.A., Vyshinsky V.V., Pashkov O.A., et al. Using the maximum pressure principle for verification of calculation of stationary subsonic flow. Herald of the Bauman Moscow State Technical University, Series Mechanical Engineering, 2019, no. 6, pp. 4-16.

31. Babaytsev, A.V., Orekhov, A.A., Rabinskiy, L.N. Properties and microstructure of AlSi10Mg samples obtained by selective laser melting// Nanoscience and Technology: An International Journal, 2020, 11(3), p. 213-222.

32. Egorova, O.V., Kyaw, Y.K. Solution of inverse non-stationary boundary value problems of diffraction of plane pressure wave on convex surfaces based on analytical solution//Journal of Applied Engineering Science, 2020, 18(4), p. 676-680.

33. Formalev, V.F., Kolesnik, S.A., Selin, I.A. Local non-equilibrium heat transfer in an anisotropic halfspace affected by a non-steady state point heat source // Herald of the Bauman Moscow State Technical University, Series Natural Sciences. 2018. 80(5), p. 99-111.

34. Zaripov R.N., Murakaev I.M., Novikov S.V., Ryapukhin A.V. Corporate Structure for Innovative Enterprises, Russian Engineering Research, 2020,Vol. 40, I. 2, pp. 137-139.

35. BurovaA.Yu.,Ryapukhin A.V.,Muntyan A.R. Reduced hardware costs with software and hardware implementation of digital methods multistage discrete Fourier transform on programmable logic devices, Amazonia Investiga, 2020, Vol. 9, I. 27, pp. 227-233.

36. Kolesnik, S.A., Bulychev, N.A., Rabinskiy, L.N., Kazaryan, M.A. Mathematical modeling and experimental studies of thermal protection of composite materials under high-intensity effects of laser radiation// Proceedings of SPIE - The International Society for Optical Engineering. 2019. 11322, article number $113221 \mathrm{R}$.

37. Rabinskiy, L.N. Non-stationary problem of the plane oblique pressure wave diffraction on thin shell in the shape of parabolic cylinder// Periodico Tche Quimica, 2019, 16(32), p. 328-337.

38. Dobryanskiy, V.N., Rabinskiy, L.N., Tushavina, O.V. Experimental finding of fracture toughness characteristics and theoretical modeling of crack propagation processes in carbon fiber samples under conditions of additive production// Periodico Tche Quimica, 2019, 16(33), p. 325-336. 